\title{
Entre o tipo e a norma: reflexões sobre o comportamento do designer gráfico no ambiente acadêmico
}

\author{
Somewhere between the type and the norm: reflections on the behavior of the graphic \\ designer in the academic environment
}

Ismael Lopes Mendonça

Mestrando em Ciência da Informação pela Universidade Federal do Ceará - UFC. E-mail: ismaelmendonca@gmail.com

Luiz Tadeu Feitosa

Doutor em Sociologia pela Universidade Federal do Ceará - UFC. Professor do Programa de Pós-graduação em Ciência da Informação da Universidade Federal do Ceará - UFC. E-mail: tadeu.feitosa62@gmail.com

\begin{abstract}
Maria de Fátima Oliveira Costa
Doutora em Ciência da Informação pela Universidade Estadual Paulista - UNESP. Professor do Programa de Pós-graduação em Ciência da Informação da Universidade Federal do Ceará - UFC. E-mail: fatima12oliveiracosta@gmail.com
\end{abstract}

\begin{abstract}
Resumo
Este estudo exploratório busca compreender como os designers gráficos, especialistas em mediar informações pelo aspecto simbólico da tipografia, comportam-se diante dos mecanismos ordenadores do texto científico. Parte-se do pressuposto de que as convenções normativas, ao estabelecerem uma estética padronizada, restringem o potencial significante dos tipos a modelos preconcebidos. Diante disso, deseja-se saber como os designers que atuam no ensino superior lidam com essa questão, se eles resistem ao serviço de normalização e que soluções podem ser apresentadas a fim de melhorar ou alterar os padrões atuais. Em campo, optou-se por trabalhar com o grupo "Professores de Tipografia" do Facebook ${ }^{\mathrm{TM}}$, pois reúne designers docentes de diferentes instituições brasileiras, além de algumas internacionais. Foi disponibilizado para eles um questionário digital criado pelo Google Forms ${ }^{\mathrm{TM}}$, cujo conteúdo das respostas foi analisado com base no conceito de regime de informação de Frohmann (1995) e de González de Gómez (2012). Pelo retorno obtido, percebe-se que as ações e as opiniões dos depoentes apresentam marcas do regime ordenador científico, configurando-lhes um comportamento acadêmico condicionado pela norma, a despeito de suas habilidades como comunicadores visuais. Conclui-se que, apreendidos por esse sistema, os depoentes não somente seguem as prescrições normativas, mas as reforçam, ampliando o poder regulatório consolidado no rigor estrutural do texto, na escrita objetivada e na funcionalidade operacional dos meios que armazenam e recuperam a informação.
\end{abstract}

Palavras-chave: Design gráfico - aspectos sociais. Mediação cultural. Normalização. Documentação científica. Regime de informação.

\begin{abstract}
This exploratory research seeks to understand how graphic designers, specialists in mediating information by the symbolic aspect of typography, behave dealing with the ordaining mechanisms of the scientific text. The assumption is that normative conventions, in establishing a standardized aesthetic, restrain the significant potential of types towards preconceived models. In view of this, we want to know how designers working at the academic environment deal with this issue, whether they resist the standardization service and what solutions can be presented in order to improve or change current standards. In the field, we chose to work with the Facebook ${ }^{\mathrm{TM}}$ group so called "Professores de Tipografia" (Typography Teachers), as it gathers teaching designers from different Brazilian institutions, as well as some international ones. They were provided a digital questionnaire created by Google Forms ${ }^{\mathrm{TM}}$, whose content of the answers was analyzed based on the concept of information regime by Frohmann (1995) and González de Gómez (2012). By the data obtained from the questionnaire, it is perceived that the actions and the opinions of the deponents present marks of the scientific ordaining regime, configuring to them an academic behavior conditioned by the norm, in spite of their abilities as visual communicators. It is concluded that chained to this system, the deponents not only follow the normative prescriptions, but reinforce them, expanding the consolidated regulatory power in the structural rigidity of the text, and also in the objective writing and the operational functionality of the means that retain and retrieve the information.
\end{abstract}

Keywords: Graphic design - social aspects. Cultural mediation. Normalization. Scientific documentation. Regime of information.

InCID: R. Ci. Inf. e Doc., Ribeirão Preto, v. 9, n. 1, p. 72-92, mar./ago. 2018.

DOI: 10.11606/issn.2178-2075.v9i1p72-92 


\section{Introdução}

Os estilos tipográficos são diversos. Eles são originários da história da escrita, das experiências em torno das ferramentas e das tecnologias empregadas. Tem-se, por exemplo, o uso do cinzel na antiguidade, que esculpiu os primeiros desenhos, a pena da Idade Média, que desenvolveu os traços cursivos, os tipos móveis da Renascença em diante, que prezaram pelas serifas e pelo equilíbrio clássico e formal, e o computador moderno, que possibilitou hibridismos digitais, mesclas tipográficas, a qualquer um. Assim, desde os tempos imemoriais, cada técnica tem configurado características particulares ao modo de compor e de escrever, gerando novas formas de expressão.

Acredita-se, porém, que os instrumentos da escrita, por si só, não poderiam propiciar tamanha gama de linguagem se não houvesse, a lhes condicionar, as relações culturais e os regimes simbólicos cultivados em cada fase. Advêm dessas relações, as convenções que têm elegido certos usos, criado representações e valorizado identidades em detrimento de outras. É o caso da ornamental caligrafia gótica, reverenciada pelo poder eclesiástico medieval, que perdeu hegemonia para a clássica letra romana dos letrados pós-Gutenberg, a qual, por sua vez, foi substituída pelo geometrismo racionalista do início do século XX. Por isso, para além da expressividade técnica, os contextos históricos dos tipos têm promovido maneiras diversas de mediar mensagens.

Para dar conta do arsenal estilístico que a cultura e os meios técnicos têm possibilitado, operacionalizando-o de modo a construir significados que se traduzem em informações, é que o designer gráfico, profissional habilitado a atuar no campo do design, tem se estabelecido e desenvolvido sua práxis (VILLAS-BOAS, 2007). Ou seja, é pelo manejo dos tipos e de outros códigos visuais, como a fotografia e a ilustração, que o designer realiza seu papel de comunicar e de mediar sentidos a partir de seu trabalho, na construção de seus projetos.

No ambiente das produções científicas, entretanto, o perfil criativo desses profissionais que atuam como docentes em universidades precisa se submeter aos rigores normativos que vigoram na academia. Esses locais prezam por um modelo formal de comunicação em vista de padronizar e viabilizar a informação científica. No Brasil, segue-se como referência o que preconiza a Associação Brasileira de Normas Técnicas (ABNT), foro nacional de normalização, tendo seus desdobramentos a cargo das instituições acadêmicas, universidades e editorias científicas que aplicam e fiscalizam o uso das Normas Brasileiras (NBRs). 
É o caso da ABNT NBR 14724 (ASSOCIAÇÃO..., 2011a, p. 10), que trata da apresentação padronizada dos trabalhos acadêmicos, onde é recomendado o uso de uma "fonte tamanho 12 para todo o trabalho, [...] excetuando-se citações com mais de três linhas, notas de rodapé, paginação, dados internacionais de catalogação-na-publicação, legendas e fontes das ilustrações e das tabelas, que devem ser em tamanho menor e uniforme", além de promover outras regras estruturais de âmbito geral. O mesmo ocorre na ABNT NBR 15287 (ASSOCIAÇÃO..., 2011b), que normaliza a apresentação dos projetos de pesquisa.

Entretanto, se a ABNT não estabelece qual fonte tipográfica com corpo 12 é essa, as definições surgem por parte dos editais e dos periódicos científicos, que acabam por direcionar certas escolhas. Por exemplo, das 35 revistas da área da Ciência da Informação com Qualis A e B, quadriênio 2013-2016, listadas por Araújo (2017, online) e disponíveis para acesso, 22 determinam o uso das fontes Times New Roman ou Arial no campo das diretrizes para autores, nos templates de submissão ou nas políticas de seção, tendo predominância a Times.

Diante disso, se o serviço de normalização, nesse contexto, ao inserir padronização e simplificação ao ato de elaborar trabalhos científicos "com vistas à obtenção do grau ótimo de ordem" (ASSOCIAÇÃO..., 2014, online), limita a atuação do designer como reprodutor do modelo formal acadêmico, pergunta-se: como esses profissionais especialistas no uso do tipo se relacionam com os padrões do texto científico? Há resistências ao serviço de normalização? Que soluções podem ser apresentadas por eles em vista de aprimorar ou alterar as convenções atuais da academia?

O objetivo geral desse trabalho, portanto, é compreender como se comportam os designers gráficos que atuam no ambiente de ensino universitário diante dos mecanismos de controle das comunicações científicas. Como específicos, tem-se: a) estabelecer as bases culturais dos sistemas ordenadores; b) defini-los como componentes do regime de informação ao qual a ciência se cerca; e c) refletir como esse regime informacional influencia na atuação dos designers. Para subsidiar as análises e as discussões da experiência, serão utilizados os textos de Elias (1996), Geertz (2015), Foucault (2014), Frohmman (1995; 2008) e González de Gómez (2012).

Este estudo se sustenta no paradigma social da Ciência da Informação, que considera seu objeto, a informação, como um fenômeno social e culturalmente mediado (ALMEIDA JÚNIOR, 2009; CAPURRO; HJØRLAND, 2007). Assim, os designers considerados nesse estudo são usuários reais da informação tipográfica e científica e agem de maneira 
contextualizada aos locais e aos sistemas onde atuam, ou seja, em diálogo com "as plurais gramáticas socioculturais" dos contextos, que por sua vez se desdobram "numa diversidade de mediações e linguagens” (GONZÁLEZ DE GÓMEZ, 2012, p. 25).

\section{A cultura como sistema ordenador}

No âmbito das Ciências Sociais aplicadas, em que a Ciência da Informação possui locus, tratar dos mecanismos de controle da comunicação científica, e de como interferem no comportamento dos designers, reclama reconhecer a existência de um sistema ordenador anterior, que atua no campo da cultura e que lhes fornece base de operação. Diante disso, a teoria do processo civilizatório, desenvolvida pelo sociólogo alemão Norbert Elias (1996), possibilita um ponto de partida para a abordagem.

Para Elias (1996), a formação da sociedade moderna ocidental se deu a partir das ações de civilização, cuja sociogênese remete aos manuais de etiqueta do século $\mathrm{XV}$, do qual a elite emergente fazia uso para se relacionar nos espaços restritos à corte. Esse código de distinção social não somente ordenava os cortesãos, estabelecendo ideais de decoro e de virtude, mas possibilitava sociabilidades mais amplas guiadas em torno da economia de afetos, forçando culturas bárbaras tradicionais (kultur) a se unificarem e integrarem o projeto de uma sociedade nacional, desenvolvida e civilizada.

"Até certo ponto, o conceito de civilização minimiza as diferenças nacionais entre os povos: enfatiza o que é comum a todos os seres humanos ou - na opinião dos que o possuem deveria sê-lo", afirma Elias (1996, p. 25). Como um sistema de ordenação social, esse conceito "veio, também, a sintetizar a nação, a expressar a auto-imagem (sic) nacional [...] como um brado de união por todo o mundo" (ELIAS, 1996, p. 64). Assim, o processo civilizatório se configurou como o modo pelo qual as sociedades ocidentais se estabilizaram e prosperaram, tecendo uma complexa rede de controles e de exclusões que reverberou pelo modo de vida moderno.

Geertz (2015), autor de "A interpretação das culturas", também enxerga o mundo orientado por densas malhas culturais. Seu conceito, porém, não permite pensar a cultura como um regime deslocado a ditar sobre o homem. Antes, traz ambos, a cultura e o homem, para dentro do mesmo plano dialógico. Por suas palavras: 
Como sistemas entrelaçados de signos interpretáveis [...], a cultura não é um poder, algo ao qual podem ser atribuídos casualmente os acontecimentos sociais, os comportamentos, as instituições ou os processos; ela é um contexto, algo dentro do qual eles podem ser descritos de forma inteligível - isto é, descritos com densidade. (GEERTZ, 2015, p. 10).

E, conforme acrescenta:

Na tentativa de lançar tal integração do lado antropológico e alcançar, assim, uma
imagem mais exata do homem, quero propor duas ideias. A primeira delas é que a
cultura é melhor vista não como complexos de padrões concretos de comportamento
- costumes, usos, tradições, feixes de hábitos -, como tem sido o caso até agora, mas
como um conjunto de mecanismos de controle - planos, receitas, regras, instruções (o
que os engenheiros de computação chamam 'programas') - para governar o
comportamento. A segunda ideia é que o homem é precisamente o animal mais
desesperadamente dependente de tais mecanismos de controle, extragenéticos, fora da
pele, de tais programas culturais, para ordenar seu comportamento. (GEERTZ, 2015,
p. 32-33).

Assim, a cultura como regime simbólico não deve ser confundida como um composto de leis empíricas que aferem causalidades dos problemas humanos. Como sistema ordenador, a cultura permite que os indivíduos criem laços significativos por meio dos quais as experiências cotidianas são organizadas e se tornam memória e tradição. É pela direção dos sistemas culturais que o homem tem construído seu caminhar na Terra, no plexo de suas relações intersubjetivas, garantindo senhas para o futuro. Por isso a cultura é um programa em constante atualização, um processo contínuo de hibridez de práticas humanas discretas (CANCLINI, 2015) a condicionar a vida social para além dos determinismos impostos a ela (LARAIA, 2009).

O sistema de ordenação cultural, apresentado brevemente aqui pelo processo civilizador de Elias (1996) e pelas teias de significação de Geertz (2015), serve de guia para os contextos humanos e suas produções. É aos códigos culturais que o homem recorre para suprir suas limitações naturais, construir sentidos, estabilizar-se e se sociabilizar em grupos. Esse processo é dialógico e interdependente, ou seja, do mesmo modo que sem cultura não haveria homens, sem homens também não haveria cultura. 


\section{O regime da informação científica} ambiente acadêmico

Se a cultura se vale da interação entre atores e seus contextos, permitindo relações programáticas de duplo afetamento que, para além da instituição de leis frias, são plenamente renováveis (GEERTZ, 2015), o fazer científico tende a se materializar na forma de mecanismos rígidos de controle a guiar "vontades de verdade". A vontade de verdade é um conceito apresentado por Foucault (2014) em "A ordem do discurso" e se refere ao desejo humano inalienável de apreender verdades por meio de aparelhos discursivos. Para o autor (2014, p. 10), discurso e vontade estão imbricados porque "discurso não é simplesmente aquilo que traduz as lutas ou os sistemas de dominação, mas aquilo porque, pelo que se luta, o poder do qual nos queremos apoderar".

Vontade de verdade, portanto, não é somente vontade de conhecer e de usufruir de conhecimento, mas de construir um conhecimento de modo excludente, que rejeite tudo o que se apresente contrário à ordem do próprio desejo. Essa vontade age "como uma prodigiosa maquinaria destinada a excluir todos aqueles que, ponto por ponto, em nossa história, procuraram contornar essa vontade de verdade e recolocá-la em questão contra a verdade" (FOUCAULT, 2014, p. 19-20). Os sujeitos do discurso operacionalizam suas vontades de verdade por meio da disciplina, que significa:

[...] um domínio de objetos, um conjunto de métodos, um corpus de proposições consideradas verdadeiras, um jogo de regras e de definições, de técnicas e de instrumentos [...] uma espécie de sistema anônimo à disposição de quem quer ou pode servir-se dele, sem que seu sentido ou sua validade estejam ligados a quem sucedeu ser seu inventor. (FOUCAULT, 2014, p. 28-29).

A disciplina, como mecanismo útil ao controle de vontades e discursos, está inserida na proposta documental de Otlet. Em “The role of facts in Paul Otlet's modernist project of documentation", Frohmann (2008) afirma que Otlet interpretava do mesmo modo os fenômenos presentes na natureza e nas relações sociais. Para ele, o fato, a essência dos fenômenos, careceria de rigor disciplinar sobre a escrita científica e sobre os processos de produção documental para que, estabilizada a cadeia de signos, pudesse ser revelado e apreendido. Pelas palavras do autor: 
Science is built upon writing, but its writing must be made more scientific. The clear and accurate revelation of results requires that scientific writing be disciplined, controlled, standardized, regularized, catalogued and classified according to a uniform, universal set of techniques whose rigour and objectivity find their ultimate expression when documentary operations function like assemblages of machines. ${ }^{1}$ (FROHMANN, 2008, p. 78).

Além disso, conforme continua:

[...] facts are simple, but the signs of facts are not. [...] The labour of revealing the order of facts according to scientific laws can then proceed 'naturally', unobstructed by the inefficiencies of wasteful duplication and lost, undocumented and unorganized facts. Much work has to be done, many techniques and practices need to be developed, many workers need to be trained, and many interlocking institutions must be created in order to stabilize the chains of signs that constitute the proper, analytical documentation of facts. ${ }^{2}$ (FROHMANN, 2008, p. 82).

Se o rigor normativo e disciplinar das produções científicas for tomado como um regime pelo qual a ciência se fortalece, não apenas a escrita, mas os escritores também estariam condicionados a ele. Essa noção alude ao conceito de regime de informação da Ciência da informação que, para Frohmann (1995), em "Taking information policy beyond Information Science", é definido como o modo pelo qual os fluxos da informação se comportam como redes mais ou menos estáveis asseguradas por canais determináveis. Nas palavras do autor: "Let us therefore call any more-or-less stable system or network in which information flows through determinable channels - from specific producers, via specific organizational structures, to specific consumers or users - a régime of information"3 (FROHMANN, 1995, p 5-6, grifo do autor).

Já por González de Gómez (2012), o regime de informação é apresentado como:

[...] modo de produção informacional dominante numa formação social, que prescreve sujeitos, instituições, regras e autoridades informacionais, meios e recursos preferenciais de informação, padrões de excelência e critérios para seu processamento seletivo. (GONZÁLEZ DE GÓMEZ, 2012, p. 32)

\footnotetext{
${ }^{1}$ Tradução livre: “A ciência é construída com base na escrita, mas a sua escrita deve ser mais científica. A revelação clara e precisa dos resultados requer que a escrita científica seja disciplinada, controlada, padronizada, regularizada, catalogada e classificada de acordo com um conjunto uniforme e universal de técnicas cujo rigor e objetividade encontram sua máxima expressão quando as operações documentais funcionam como montagens de máquinas".

2 Tradução livre: “[...] os fatos são simples, mas os seus sinais não são. [...] O trabalho de revelar a ordem dos fatos de acordo com as leis científicas pode então prosseguir 'naturalmente', desobstruído das ineficiências dos fatos duplamente desperdiçados e perdidos, não documentados e nem organizados. Muito trabalho tem sido feito, muitas técnicas e práticas precisam ser desenvolvidas, muitos trabalhadores precisam ser treinados e muitas instituições interlocutoras devem ser criadas na ordem de estabilizar as cadeias de sinais que constituem a documentação analítica adequada dos fatos".

${ }^{3}$ Tradução livre: "Por conseguinte, chamemos qualquer sistema ou rede mais ou menos estável em que a informação flua através de canais determináveis - de produtores específicos, através de estruturas organizacionais específicas, para consumidores ou usuários específicos - um regime de informação".
}

InCID: R. Ci. Inf. e Doc., Ribeirão Preto, v. 9, n. 1, p. 72-92, mar./ago. 2018. 
Pelo conceito de regime da informação construído por Frohmann (1995) e González de Gómez (2012), não somente a informação em si, mas também os seus usuários e todo o comportamento informacional resultante das interações nas e pelas cadeias de produção e difusão estariam condicionados à ordem pela qual o regime está estabelecido, à ordem ditada por um poder, ou grupo de poder, dominante. Nesse tocante, as produções acadêmicas se configuram como regime de informação, que estrutura, estabiliza e controla códigos e cientistas, a partir das ações de normalização. Aí está diluída a noção de eficiência a partir da prática ordenadora e disciplinadora dos documentos acadêmicos. Uma eficiência sistêmica e operacional a imperar sobre o modo de fazer científico e sobre os profissionais da ciência.

\section{Procedimentos metodológicos}

A pesquisa não intenta somente descrever as respostas do grupo investigado, mas refletilas tendo como base discursiva o referencial teórico construído, a fim de compreender o comportamento dos designers acadêmicos diante da necessidade de normalizar as produções científicas e lançar bases para uma investigação futura mais ampla. Diante disso, cabe dizer que o estudo possui uma natureza exploratória, de base social e antropológica. Pesquisas classificadas com essa característica, segundo Gil (2008, p. 27), "têm como principal finalidade desenvolver, esclarecer e modificar conceitos e idéias (sic), tendo em vista a formulação de problemas mais precisos ou hipóteses pesquisáveis para estudos posteriores”.

Do universo de designers que atuam em instituições de ensino superior brasileiras, foram escolhidos aqueles que tivessem experiência no ensino de tipografia, haja vista que o serviço de normalização incide diretamente sobre a estética das composições, criando rígidos padrões tipográficos. Assim, supostamente, dentre os designers acadêmicos, os especialistas em tipografia seriam os mais prejudicados pela aplicação da norma técnica dos textos científicos e, ao mesmo tempo, os que melhor poderiam argumentar sobre os padrões tipográficos, sugerindo inclusive possibilidades de reconfiguração ou melhoria do sistema normativo.

Diante disso, optou-se por trabalhar os designers que fazem parte do grupo "Professores de Tipografia", uma comunidade secreta do Facebook ${ }^{\mathrm{TM}}$, criada em 24 de novembro de 2016 e formada atualmente por 83 membros. O grupo é originário de outro maior, chamado “Tipocracia”, grupo público do Facebook ${ }^{\mathrm{TM}}$ que reúne mais de 5.000 membros. Ambos são 
administrados por Henrique Nardi, designer e educador na área. $\mathrm{O}$ acesso ao grupo se deu a convite do próprio administrador, que ao ser consultado sobre a possibilidade da realização dessa pesquisa no "Tipocracia", recomendou o de professores por ser formado exclusivamente de designers tipógrafos, atuantes no meio acadêmico.

A comunidade escolhida é descrita por seu administrador como "Um grupo para falarmos sobre educação tipográfica: exercícios, bibliografia, planos de ensino, pesquisa, etc.”, está classificada como "Escola ou turma” e representada pelas tags: "Typography. Teachings. Research. Educação". As postagens giram em torno de dicas metodológicas para o ensino de tipografia, divulgação de trabalhos e eventos acadêmicos da área, pedidos de contribuição em pesquisas e lançamentos de livros, dentre outros temas relacionados à prática do ensino. $\mathrm{O}$ grupo é heterogêneo, formado por homens e mulheres de faixas etárias diversas, procedentes de diferentes regiões brasileiras e com titulação acadêmica variada: constam doutores, mestres, especialistas e graduados.

Tendo em vista tratar-se de um grupo virtual, cujos membros estão geograficamente dispersos, escolheu-se por utilizar como instrumento de coleta de dados um questionário digital criado pela ferramenta Google Forms ${ }^{\mathrm{TM}}$. Ele contém ao todo oito questões, sendo três objetivas e cinco subjetivas planejadas de modo a contemplar os objetivos da pesquisa, além de uma final para o registro facultativo de e-mail ou telefone para contato posterior. A postagem do questionário foi realizada no dia 16 de janeiro de 2017 e ficou disponível ao grupo até o dia 2 de fevereiro de 2017. Do retorno, dez designers responderam o questionário, dentre os 48 que visualizaram a postagem, conforme registrava a rede social no dia da apuração dos resultados. 


\section{Análise e discussão dos resultados} ambiente acadêmico

Pelas questões objetivas, constatou-se a heterogeneidade prevista no grupo. Dentre os dez que participaram da pesquisa, tem-se que dois são doutores, sete são mestres e um é pósgraduado (lato sensu). Todos lecionam ou já lecionaram tipografia em Instituição de Ensino Superior (IES) e somente três nunca pesquisaram sobre os tipos.

A intenção com essa tríade também foi verificar se ocorre relação direta entre o grau de especialização dos designers (traduzido pelas ações de ensino e pesquisa na área, além da titulação acadêmica) e o condicionamento ao regime da informação científica (aferido pelas ações descritas ao longo das questões subjetivas). Os resultados, porém, são díspares, como pode ser visto nas descrições abaixo.

Os dois doutores (D1 e D2) seguem as orientações normativas na hora de escolher a fonte tipográfica dos trabalhos científicos. Porém, enquanto D1 se sente "como um jogador de futebol que tem que usar o uniforme do time" diante dos padrões do texto científico, procurando não driblá-los, D2 se posiciona de modo inverso, "triste em perceber a arbitrariedade e a falta de rigor de quem propôs a norma", realizando mudanças sempre que possível na norma, "conforme a boa conduta das tradições tipográficas".

D3, D4, D5, D6, D7 e D8 são mestres, possuem pesquisa em tipografia e escolhem a fonte de seu texto pelo que prescreve a norma das submissões. Enquanto D3, D4, D5, D6 e D7 se sentem incomodados e limitados com o atual padrão tipográfico da academia, D8 não vê problema nele, pois "se fosse de livre escolha seria uma bagunça", seguindo-o, pois, à risca. D4, D5, D6, e D7, mesmo incomodados, não interferem no modelo normativo tendo em vista se tratar de um requisito para publicação. Já D3 afirma que sim, sempre que possível, faz suas escolhas.

Portanto, a disparidade nas respostas, própria das pesquisas de natureza qualitativa, revelam não haver relação direta entre as variáveis "especialização do designer" e "condicionamento à norma". Entretanto, pelo todo da pesquisa, percebe-se a existência de marcas do regime de informação a conduzir as ações e as opiniões dos inquiridos. Diante disso, para evidenciar melhor essas marcas e refleti-las no comportamento dos designers, será feita a análise de cada uma das questões abertas. 


\subsection{A tipografia para os designers}

Desde o surgimento da prensa móvel, várias são as definições aplicáveis aos tipos: de técnica de composição e reprodução de textos, bem como o lugar onde são feitas as impressões (ARAÚJO, 1986) à nova maneira de escrever e de pensar (FLUSSER, 2010). Assim, buscouse saber o que a tipografia representa para cada designer. Diante das respostas coletadas, percebe-se que as definições e os sentidos em torno do que a tipografia significa para eles são aplicáveis ao conceito de regime de informação.

Para D1, tipografia é "a arte e a técnica de produzir fontes tipográficas ou compor informação com elas". Compor informação pode significar que, para além do ato de construir produtos (fontes tipográficas, páginas impressas, informações como "coisas” materiais), existe também a possibilidade de mediar seus efeitos, os símbolos que, traduzidos, remetem a pensamentos e interações. Isso anunciaria o papel de mediação tipográfica, uma mediação informacional e cultural pelos tipos. Além disso, o ato de compor informações reclama por algo que ordene a técnica, regule a estética, traduza os sentidos e estabeleça funções à composição. Esse algo pode ser compreendido como uma ação do regime de informação a estabelecer as bases determináveis dos processos de registro, mediação e interação tipográficos.

D2 afirmou que a tipografia "é [e] sempre foi uma das principais tecnologias já inventadas. Sem a tipografia nem a cultura nem a ciência florescem". Como tecnologia, a tipografia seria um meio a serviço da cultura e da ciência, uma ferramenta a representar os seus interesses, não somente nos registros, mas nas mediações. Essa definição circunscreve os tipos novamente dentro do regime de informação pelo qual a cadeia de significações tipográficas se estabiliza e se torna operacional. Ou seja, a tipografia estaria a alimentar e a reforçar a cultura e a ciência, possibilitando-as florescer, ao mesmo tempo em que estaria impregnada de seus sentidos e ordenações.

D5, ao destacar que, "para além da sua expressividade, estudo e ensino tipografia por sua importância na compreensão de conceitos fundamentais do design" acrescenta à função mediadora dos tipos a sua inserção dentro da política informacional da área do design: as teorias do campo, sua epistemologia e metodologia etc. Assim, se o design surgiu "com o firme propósito de pôr ordem na bagunça do mundo industrial" (CARDOSO, 2012, p. 15), projetando soluções para as demandas desse mundo, a tipografia seria um componente ativo nessa função de “de-signar" (FLUSSER, 2007, p. 181), de atribuir ordem e sentido ao mundo. 
Para D7, que afirmou ser a tipografia "uma maneira de pensar e conceber o projeto gráfico", para D8, que a definiu como "poderosa ferramenta de comunicação", para D9, com sendo "a "forma sólida da linguagem", e para D10, que disse se tratar de "suporte para produção de design gráfico", o aspecto simbólico e instrumental da tipografia aparecem novamente em sintonia com a política do campo, suas determinações e orientações e, por consequência, com seu regime informacional. Esse regime seria, então, o modo pelo qual o universo simbólico da tipografia, manifestado pelas composições e ordenamentos formais, é cofigurado de modo a alcançar resultados eficientes junto aos meios de produção, aos produtores e aos leitores ou consumidores, ou usuários, das mensagens.

Quanto aos demais designers, eles definiram os tipos a partir de sua função social. D3 disse que tipografia é "minha carreira", D4 a definiu como "meu trabalho" e D6, que a "tipografia é meu campo de pesquisa, diversão e trabalho". Isso possibilita pensar que, mais do que um ganha-pão ou um serviço que demande esforço e energia, a tipografia é a atividade em torno da qual esses designers se organizam, interagem e se sociabilizam. Esse é um dos sentidos relacionados ao termo "trabalho" (DICIONÁRIO..., 1987), mas também é um dos aspectos pelos quais a cultura ordinária tece suas teias de sentidos entre as coisas, os atos e as pessoas, como também o modo pelo qual os regimes de informação agregam os sistemas, os sujeitos e os comportamentos em sua complexa rede informacional.

\subsection{Escolhas convencionadas}

Pela quinta pergunta do questionário, "Nas produções científicas, qual fonte tipográfica você utiliza? Poderia justificar?”, procurou-se verificar se as escolhas tipográficas obedecem aos regimes e às ordenações simbólicas das comunicações científicas. Pela maioria das respostas, sim: oito declarantes seguem o que prescreve a norma e, caso não encontrem prescrição, escolhem com base no que já se convencionou adotar por ela: o uso das fontes Arial ou Times New Roman.

D1 segue “o padrão da publicação em questão". D2 afirmou que "em geral, por imposições normativas, uso a Times New Roman”. D3 raramente escolhe a fonte, pois “geralmente ela é determinada pelo periódico/anais em que está sendo publicada". D4 afirmou sempre utilizar "de acordo com a ABNT ou [a] formatação especificada do congresso ou revista”. D5 disse "não fujo do indicado". D6 respondeu empregar "a fonte e a diagramação 
que o edital me determinar", e continua: "Caso não existam parâmetros, emprego a Arial [...]. Desde modo, o conteúdo fica acessível a todos e não sofrerei angústias". Para D7, "geralmente Times ou Arial, por indicação nos editais para submissão de artigos”, e D8 apenas registrou "Arial".

Essas respostas sugerem que os designers, influenciados pelo rigor normativo que exclui outras formas de pensar, compor e mediar informações pela tipografia nos trabalhos acadêmicos, mostram-se condicionados aos ditames estéticos estabelecidos para o texto científico. E esse condicionamento é tal que, mesmo não havendo uma $\mathrm{ABNT}$ NBR que especifique o uso das fontes Arial e Times New Roman, ou qualquer outra, para as comunicações acadêmicas, eles, notadamente D4 e D6, preferem reproduzir o que os editais e as diretrizes editoriais, em peso, consagram, no lugar de inovar, quando poderiam, nesse quesito de escolha tipográfica. Com isso, a lógica do padrão, marca do regime da informação científica, impera tanto sobre os critérios de seleção do tipo e de formatação dos textos, como sobre os próprios designers que, de sujeitos do regime, passam também a atuar como colaboradores desse rigoroso sistema, ao aplicar e reforçar as convenções normativas.

As prescrições da norma, na visão de Frohmann (1995), funcionam como nós ou pontos sob os quais do regime de informação se estabiliza. São formas específicas de dominação implicadas no exercício do poder na, pela e sobre a informação. Assim, elas atuam junto ao condicionamento dos usos e dos usuários da informação tendo em vista que, por meio delas, "poder e controle suficientes são exercidos sobre os componentes dos sistemas de informação" (FROHMANN, 1995, p. 5, livre tradução).

Quanto aos dois designers que supostamente não se encaixariam nesse perfil, D9 e D10, por terem dito que escolhem com base no gosto pessoal, há de se pensar no quão inseridos estão no contexto acadêmico, se ambos submetem trabalhos com frequência e se as instituições onde eles atuam como docentes estão regulamentadas pelo regime. Infelizmente, essas questões não foram contempladas no questionário. Mas pela análise das próximas perguntas, pode-se afirmar que o regime da informação científica acomete contra os dois tanto quanto aos demais. 


\subsection{Os sentimentos em relação à norma} ambiente acadêmico

“Como você se sente diante dos padrões tipográficos do texto científico?”, foi a sexta pergunta feita aos designers. No percurso reflexivo sobre o condicionamento sujeito à norma $\mathrm{e}$ ao regime de informação que ela integra, os designers puderam relatar como se sentem diante da realidade acadêmica. Pela análise das respostas, os designers da pesquisa podem ser divididos aqui em pelo menos dois grupos.

Em primeiro lugar, há os que se colocaram indiferentes à norma. Nesse grupo, estão presentes D1, que se comparou ao um jogador de futebol, D8, que defendeu a existência da norma para que tudo não virasse uma bagunça, D9, que interpreta a norma como "uma maneira de ajudar aos não iniciados a deixar clara a hierarquia do texto", e D10, que registrou apenas "não me incomoda". Para além de um mero conformismo desses designers ao rigor dos padrões tipográficos do texto científico, vale aqui replicar o que já dito há pouco: o regime de informação, em que a ciência e seus sistemas ordenadores estão inseridos, dita sobre as escolhas dos designers acadêmicos, condicionando os usos, os comportamentos e toda a cadeia produtiva que irá abastecer os sistemas de informação.

Esse condicionamento se consolida diante da necessidade que a carreira acadêmica lhes impõe de produzir e publicar trabalhos. Assim, reféns do regime, os designers não possuem outra saída a não ser se submeterem a ele, garantindo, por um lado, a progressão de suas carreiras e, por outro, a estabilidade e a manutenção da rede de controle informacional. O poder emanado por essa cadeia acomodaria os designers no âmbito de sua produção científica e azeitaria, pela linguagem padronizada dos documentos, as peças do sistema que, sem ela, tornar-se-iam inoperantes.

Que outra razão justificaria essas respostas? Se o designer é especialista e competente em mediar mensagens complexas pelo uso da tipografia, lançando mão de sua inventividade e domínio técnico, por que se mostraria indiferente à norma que lhe tolhe o espírito criativo e o subutiliza como reprodutor de padrões? O mais provável era encontrar queixas nas respostas, reclamações, como se observa em D2, D3, D4, D5, D6 e D7. Esses designers constituem o segundo grupo de depoentes: os que revelaram insatisfação diante da norma e lamentaram o fato desses padrões desprezarem os fundamentos tipográficos tradicionais, "que promovem a composição do texto de qualidade" (D2), e por não possuírem, nas agências normalizadoras, "um designer especialista em tipografia e leiturabilidade" (D3). 
Percebe-se, porém, entre os descontentes, não um sentimento de indignação ou contestação ao formato padronizado do texto científico, mas ao modo como o modelo atual disponível está configurado. Assim, suas queixas não são para que o padrão deixe de ser exigido, mas para que se torne "melhor" (D3), desejando "que novos modelos fossem tentados" (D4), o que evidencia marcas do regime da informação científica no perfil dos designers, além da ocorrência de elos de interdependência entre eles e o sistema ordenador do regime.

\subsection{Acerca das transgressões}

A sétima pergunta, "Você procura driblar o padrão tipográfico normativo na hora de compor seus trabalhos científicos? Se sim, pode nos dizer como faz?", bebe da referência de Flusser (2007, p. 182), quando diz que o designer é "um conspirador malicioso que se dedica a engendrar armadilhas", e de González de Gómez (2012, p. 30-31), ao afirmar que o conceito de regime de informação:

[...] oferece uma nova moldura teórica que, ao dar maior amplitude às questões relevantes e pertinentes aos domínios do informacional, permite indagar - nesse domínio - a construção de novas subjetividades, os processos formais e informais de enunciação de demandas e de elaboração de políticas, dando visibilidade a novos parâmetros de análise [...].

Diante disso, o que se objetiva nessa seção é verificar, diante das possibilidades quase nulas de enfrentamento e superação do regime ao qual se cerca a ciência, que artimanhas são possíveis de realizar a fim de imprimir, nos sistemas ordenadores, a assinatura do designer.

Nas respostas, D1, D5, D6 e D10 registraram apenas "não". D4 afirmou não perder tempo com isso, "pois para publicações terei que formatar na formatação estabelecida". D7 disse seguir rigorosamente os editais e D8 exclamou ser perda de tempo driblar a norma. Essas colocações reforçam o que já foi dito sobre o regime da informação científica imperar sobre designers, tendo em vista que, ao atuarem na academia, necessitam dele para o desenvolvimento de sua carreira como docente e pesquisador. Reforça também o sentido reflexivo dessa ação, ao se sujeitarem, os depoentes reafirmam o jogo de poder exercido por essas redes de controle. Pelas palavras de Frohmann (1995, p. 6, livre tradução): "todos esses são nós das redes informacionais, ou elementos de regimes de informação específicos”.

D9, D3 e D2, porém, encontram brechas por onde inserir suas marcas pessoais. Para D9, "um versalete aqui, ativando a hifenização no Word ali, usando os glifos certos para 
determinadas situações". Para D3, "quando é possível, sempre faço minhas escolhas, com uma boa fonte de texto, corpo adequado, largura de coluna adequada, etc.". D2 afirmou que sempre: "Procuro usar sempre entrelinhas satisfatórias e procuro chegar próximo do espaço 1,5 usando a entrelinha 50\% maior que a do corpo do texto". E conforme acrescenta: "Quando escrevo um artigo em que há uma norma pré-definida não há muito como driblar isso, mas quando se trata da diagramação de uma dissertação ou uma tese, acho importante, especialmente por escrever sobre design editorial, ter liberdade de diagramar conforme a boa conduta das tradições tipográficas".

Importante perceber que, para além do rigor disciplinar a que estão submetidos, os designers, como conspiradores maliciosos (FLUSSER, 2007), conseguem encontrar meios de comunicar suas ideias a partir do uso consciente da tipografia. Ao fazerem isso, eles investem sobre os tipos o papel de mediação de informações para além das prescrições ordenadoras, transmitindo o pensamento e demonstrando melhor as ideias. Assim, o uso do tipo possibilita que as mensagens ganhem um fluxo social (LUPTON, 2009) não restrito ao ambiente acadêmico.

A liberdade de poder diagramar os textos científicos, "conforme a boa conduta das tradições tipográficas” (D2), resultaria, portanto, em textos mais ricos de significados. Essa investida, se amplamente praticada, poderia contribuir na transformação do ambiente frio da academia em um terreno fértil para novas interações e construções científicas. Assim, mais do que meramente afrontar o rigor disciplinar, os designers constroem chaves para o florescimento de uma ciência mais humana, mais interpretativa, oferecendo meios de abordagens mais complexas aos fenômenos investigados e igualmente complexos, valorizando o campo das reflexões em detrimento dos engessamentos formais normativos. 


\section{$5.5 O$ padrão reconfigurado pelos designers} ambiente acadêmico

"Se fosse possível alterar a norma sobre a padronização tipográfica no contexto acadêmico, o que você faria?", foi a última questão colocada. Os designers, como comunicadores estetas, enxergam possibilidades criativas de informar e comunicar ideias por meio da linguagem tipográfica que os sistemas culturais têm possibilitado no decorrer da história. Como acadêmicos, porém, mantêm os pés na lógica do padrão, que viabiliza fluxos e acessos, mas condiciona toda a rede informacional, incluindo os próprios designers, à lógica disciplinar. Assim, todos os dez participantes da pesquisa sugeriram alguma modificação na norma dos textos científicos, mas a maioria focou em rearranjos estruturais do modelo atual, visando torná-lo mais atraente e interativo, portanto, tipograficamente mais eficiente.

Desse grupo, há os que focaram em aprimoramentos estéticos do novo padrão, sem mencionar questões de operacionalidade e funcionalidade diante do pragmatismo acadêmico. Tem-se D10, que sugeriu a adoção de cores, D9, que "exigiria a ativação da hifenização. Ajustaria os espaços entre linhas e entre parágrafos de maneira mais coerente [...]. Aumentaria as margens [...] para chegar a uma média de caracteres mais confortável. E aboliria a Arial”, D8, que "substituiria a Times e a Arial por Minion e Myriad" e D7, que "abriria o leque de possibilidades para uso de fontes, melhoraria os projetos gráficos como um todo, tornando-nos mais dinâmicos, menos visualmente enfadonhos".

Mas também há aqueles que, para além do ganho estético, refletiram também sobre a necessidade do novo padrão ser aplicável e de fácil acesso a todos. Desses, tem-se D6, que "melhoraria a formatação ABNT e usaria uma fonte padrão de sistema operacional multiplataforma mais interessante à disposição", D5, que "exploraria novas possibilidades de diagramação e espaçamento, além de famílias tipográficas gratuitas (para evitar pirataria) com maior número de variações", e D3, que propôs "uma nova norma, que não use Arial. Times Roman é ok, pois foi feita originalmente para leitura em jornal. [...] Poderiam ser utilizadas [também] outras fontes de sistema, como Georgia, Verdana, Calibri, Cambria, etc.”.

Identificado nesse grupo, D4 foi mais além. No intuito de estabilizar as variáveis do projeto em torno da estética, função, acessibilidade e operacionalidade, que podem ser traduzidas como marcas do regime informacional, conforme conceituado por Frohmann (1995), sugere a criação de uma família tipográfica planejada para uso acadêmico. Nas palavras do designer: “Ao escolher uma tipografia é preciso considerar a disposição e acessibilidade de 
todos, desse modo inovações não são tão viáveis. Em todo caso, o desenvolvimento de uma família tipográfica para uso de toda produção científica seria uma ótima solução - com variações de pesos".

A criação de uma família tipográfica para uso da comunidade científica se apresenta útil em vários aspectos. Ela exigiria a presença de um designer atuando junto às instituições e às agências normalizadoras, teria licença de uso liberada, serviria a multiplataformas, atenderia às exigências da academia e de seus sistemas e contribuiria com um novo formato para as comunicações científicas, imprimindo qualidade na arte de compor e de representar ideias e colaborando com leituras mais participativas e interpretativas. Uma família de caracteres pensada para atender as demandas da ciência, mas, quem sabe, poder transformá-la, mediando novas maneiras de pensar e de ordenar seu regime informacional.

Há ainda outras sugestões. D2 propôs uma reforma de consciência e não apenas de padrão. Nas palavras dele: "Mudar a padronização sem mostrar a importância do estudo da tipografia de nada vale. O estudo da tipografia é fundamental para o bom uso da mesma (sic)". No embate estabelecido entre o regime da informação científica e a liberdade criativa de sentidos, vivenciada pelo designer no ato de normalizar os textos acadêmicos, estudar tipografia possibilitaria a aquisição de uma nova consciência quanto ao uso, e às implicações simbólicas desse uso, no ambiente disciplinado pela ciência. Essa "consciência tipográfica" se apresentaria libertária, porque tornaria o usuário acadêmico, designer ou não, autônomo em relação aos padrões imperativos da norma. Assim, ele não escreveria apenas a partir deles, reforçando o regime atual, mas revolucionaria estabelecendo novas lógicas, novas maneiras de produzir ciência.

Por fim, D1 sugere mudar o sistema das produções normalizadas, retirando do homem a tarefa de escrever conforme o padrão acadêmico para transferir aos programas computacionais inteligentes, essa responsabilidade. Nas palavras dele, “esta questão é muito complexa, talvez um sistema de automação com supervisão de um profissional especializado em tipografia para textos longos". É sabido que as máquinas respondem a padrões com mais eficiência do que os humanos. Para Flusser (2010, p. 20), "há algo de mecânico no organizar, no enfileirar, e para isso as máquinas têm um desempenho melhor do que o ser humano”.

Otlet já havia anunciado que o rigor disciplinar da escrita científica, na busca de uma revelação mais clara e precisa dos fatos, somente encontrará expressão máxima "quando as operações documentais funcionarem como composições de máquinas" (FROHMANN, 2008, 
p. 78, livre tradução). Para a ABNT (ASSOCIAÇÃO..., 2014, online), "recorre-se à tecnologia como o instrumento para estabelecer, de forma objetiva e neutra, as condições que possibilitem que o produto, projeto, processo, sistema, pessoa, bem ou serviço atendam às finalidades a que se destinam". Nesse sentido, delegar às máquinas o que já é da ordem delas, por um lado, tornaria os sistemas científico e informacional ainda mais eficientes. Por outro, liberaria o homem de ter que atuar como máquina, para que ele assuma, com mais propriedade, sua condição criativa e antropológica.

\section{Conclusão}

A norma acadêmica tolhe as potencialidades simbólicas e comunicacionais da tipografia. Tolhe também a ação criativa dos designers, especialistas em explorar os recursos tipográficos na construção de suas mensagens. No exercício das funções acadêmicas, esses profissionais do tipo se deparam com a necessidade de se submeterem aos sistemas ordenadores das produções científicas, condição sine qua non para a aceitação de trabalhos e progressão em

suas carreiras. É o que pode ser percebido entre os depoentes da pesquisa realizada junto ao grupo "Professores de Tipografia" do Facebook ${ }^{\mathrm{TM}}$. Nas respostas, são encontradas marcas do sistema ordenador científico.

Esse sistema ordenador da ciência assume o papel de regime de informação, uma engendrada rede de ações humanas e sistêmicas, construída com a finalidade de controlar os fluxos, os processos e os comportamentos dos usuários de acordo com uma ordem dominante, neste caso, a das instituições científicas. Tal regime tem no padrão normativo dos documentos uma ferramenta útil para estabilizar os sentidos, mantendo a operacionalidade da cadeia. Com isso, produções e produtores, textos e designers, são mantidos cativos pela força do padrão e instrumentalizados por ele.

Haja vista o cumprimento dos objetivos da pesquisa, conclui-se que, apreendidos pelo regime, os designers não somente seguem as prescrições normativas, mas as reforçam, perpetuando o poder regulatório consolidado no rigor estrutural do texto, na escrita objetivada e na funcionalidade operacional dos meios de armazenamento e recuperação da informação. Assim, atuando conforme a pauta do regime informacional da academia, os designers não possuem muita liberdade para agirem livres do pragmatismo pelo qual a ciência e os mecanismos normativos operam, subutilizando o uso do tipo e seu potencial simbólico. 


\section{Referências}

ALMEIDA JÚNIOR, O. F. Mediação da informação e múltiplas linguagens. Tendências da Pesquisa Brasileira em Ciência da Informação, Salvador, v. 2, n.1, p.89-103, jan./dez. 2009. Disponível em: 〈https://goo.gl/6c9Fok>. Acesso em: 13 jul. 2017.

ARAÚJO, E. A construção do livro: princípios da técnica de editoração. Rio de Janeiro: Nova Fronteira; Brasília: Instituto Nacional do Livro, 1986.

ARAUJO, R. F. Revistas da Ciência da Informação (Qualis C\&I 2013-2016). Informação, tecnologia \& cultura digital. 2017. Disponível em: 〈https://goo.gl/522cjA >. Acesso em: 16 abr. 2018.

ASSOCIAÇÃO BRASILEIRA DE NORMAS TÉCNICAS. ABNT NBR 14724: trabalhos acadêmicos: apresentação. Rio de Janeiro, 2011a.

ABNT NBR 15287: projeto de pesquisa: apresentação. Rio de Janeiro, 2011 b.

Normalização: definição. 2014. Disponível em: 〈https://goo.gl/p4XGPv〉. Acesso em: 13 jul. 2017.

CANCLINI, N. G. Culturas híbridas: estratégias para entrar e sair da modernidade. 4. ed. São Paulo: EDUSP, 2015.

CAPURRO, R.; HJØRLAND, B. O conceito de informação. Perspectivas em Ciência da Informação, Belo Horizonte, v. 12, n. 1, p. 148-207, jan./abr. 2007. Disponível em: <https://goo.gl/D7PB3E >. Acesso em: 07 dez. 2017.

CARDOSO, R. Design para um mundo complexo. São Paulo: Cosac Naify, 2012.

DICIONÁRIO de ciências sociais. 2. ed. Rio de Janeiro: Fundação Getulio Vargas, 1987.

ELIAS, N. O processo civilizador: uma história dos costumes. 2. ed. Rio de Janeiro: Zahar, 1996.

FLUSSER, V. A escrita: há futuro para a escrita? São Paulo: Annablume, 2010.

O mundo codificado: por uma filosofia do design e da comunicação. São Paulo:

Cosac Naify, 2007.

FOUCAULT, M. A ordem do discurso: aula inaugural no Collège de France, pronunciada em 2 de dezembro de 1970. 24. ed. São Paulo: Loyola, 2014.

FROHMAN, B. European modernism and the information society: informing the present, understanding the past. In: RAYWARD, W. B. (Org.). The role of facts in Paul Otlet's modernist project of documentation. Hampshire: Ashgate, 2008, p. 75-88. Disponível em: <https://goo.gl/9caik5 >. Acesso em: 13 jul. 2017. 
. Taking information policy beyond information science: applying the actor network theory. In: ANNUAL CONFERENCE CANADIAN ASSOCIATION FOR INFORMATION SCIENCE, 23, 1995. Anais... Edmond, Alberta: CAIS/ACSI, 1995. Disponível em: <https://goo.gl/W1t2cA > . Acesso em: 13 jul. 2017.

GEERTZ, C. A interpretação das culturas. Rio de Janeiro: LTC, 2015.

GIL, A. C. Métodos e técnicas de pesquisa social. 6. ed. São Paulo: Atlas, 2008.

GONZÁLEZ DE GÓMEZ, M. N. As ciências sociais e as questões da informação.

Morpheus: estudos interdisciplinares em memória social, Rio de Janeiro, v. 8, n. 14, p. 1837, 2012. Disponível em: 〈https://goo.gl/muVuVy〉. Acesso em: 13 jul. 2017.

LARAIA, R. B. Cultura: um conceito antropológico. 24. ed. Rio de Janeiro: Zahar, 2009.

LUPTON, E. Pensar com tipos: guia para designers, escritores, editores e estudantes. São Paulo: Cosac Naify, 2009.

VILLAS-BOAS, A. O que é [e o que nunca foi] design gráfico. Rio de Janeiro: 2AB, 2007. 